\title{
Left Ventricular Noncompaction Complicated with Myocardial Infarction with Barth Syndrome in a Newborn
}

\author{
Gyeong Hee Yoo \\ Department of Pediatrics, Soonchunhyang University Cheonan Hospital, Soonchunhyang University College of Medicine, Cheonan, Korea
}

\begin{abstract}
Left ventricular noncompaction (LVNC) is a rare cardiomyopathy characterized by a hypertrabeculation of the left ventricle. Patients may present with heart failure, arrhythmia, and thromboembolism. LVNC may be isolated or associated with congenital heart defects. The first discovered genetic cause of isolated LVNC was Barth syndrome (BTHS), an X-linked disorder caused by taffazin (TAZ) gene mutation. BTHS is characterized by cardiomyopathy, neutropenia, skeletal myopathy, and growth delay. A newborn male baby was referred to Soonchunhyang University Cheonan Hospital due to cyanosis and dyspnea. Based on findings of cardiomegaly, ST depression, and elevated cardiac enzyme, echocardiography was done, which revealed a hypocontractile, enlarged left ventricle with distinctive trabeculation in the apex. Heparinization for the treatment of myocardial infarction and continuous infusion of milrinone was started. During hospitalization, the TAZ gene mutation was detected in the patient, his mother, and elder sister. After 3 months, the patient was discharged with heart failure medication and aspirin.
\end{abstract}

Keywords: Isolated noncompaction of the ventricular myocardium; Barth syndrome; Infant, newborn; Myocardial infarction

\section{INTRODUCTION}

Left ventricular noncompaction (LVNC) is characterized by a distinctive trabeculated LV. Barth syndrome (BTHS), a rare Xlinked recessive disorder is caused by a mutation in the taffazin (TAZ) gene. Patients with BTHS frequently demonstrate LVNC. They are at risk for heart failure, arrhythmia, and thromboembolic complication [1]. Herein, we report a newborn case of LVNC complicated with myocardial infarction with BTHS.

\section{CASE REPORT}

A 2-day-old male baby was referred due to cyanosis. Cyanosis has been observed 9 hours later after birth. The oxygen saturation checked using a pulse oximeter was around $90 \%$ at room air. $\mathrm{He}$ appeared dyspneic and was admitted to the neonatal intensive care unit. Mechanical ventilator support was applied.

He was delivered vaginally at local obstetric clinic at a gestational age of $37+4$ weeks with a birth weight of 2,980 g. Perinatal and family histories were unremarkable.

Body temperature was $36.8^{\circ} \mathrm{C}$, blood pressure was $64 / 41 \mathrm{mmHg}$, pulse rate was 149/min, and respiratory rate was 53/min. Cardiac examination revealed pansystolic murmur at the apical area. Lung sound was clear. Liver and spleen were not palpable.

A chest radiograph showed a cardiomegaly (Fig. 1). An electrocardiogram revealed normal sinus rhythm with ST depression and T wave inversion in lead V1 and V2 (Fig. 2). Laboratory studies revealed a white blood cell count of $22,080 / \mu \mathrm{L}$ (reference value, 9,100 to $34,000 / \mu \mathrm{L}$ ), hemoglobin of $18.8 \mathrm{~g} / \mathrm{dL}$ (reference value, 15 to $24 \mathrm{~g} / \mathrm{dL}$ ), platelet count $173,000 / \mu \mathrm{L}$ (reference value, 84,000 to $478,000 / \mu \mathrm{L}$ ), troponin $\mathrm{T}$ of $0.423 \mathrm{ng} / \mathrm{mL}$ (reference value, <0.1 ng/ $\mathrm{mL}$ ), creatine kinase-myocardial band $96 \mathrm{U} / \mathrm{L}$ (reference value, $<24 \mathrm{U} / \mathrm{L}$ ), pro-brain natriuretic peptide $25,945 \mathrm{pg} / \mathrm{mL}$, bicarbonate $9.6 \mathrm{mmol} / \mathrm{L}$ (reference value, 21 to $28 \mathrm{mmol} / \mathrm{L}$ ), and lactate level $31.1 \mathrm{mg} / \mathrm{dL}$ (reference value of arterial sample, 4.5 to $14.4 \mathrm{mg} / \mathrm{dL}$ ). Echocardiographic views showed the hypertrabeculation in the left ventricle (LV) apex and demonstrated compacted epicardial layer [1] and noncompacted endocardial layer [2]. The noncom-
Correspondence to: Gyeong Hee Yoo

Department of Pediatrics, Soonchunhyang University Cheonan Hospital, Soonchunhyang University

College of Medicine, 31 Suncheonhyang 6-gil, Dongnam-gu, Cheonan 31151, Korea

Tel: +82-41-570-2160, Fax: +82-41-572-4996, E-mail: yoogh@schmc.ac.kr

Received: Feb. 3, 2016 / Accepted after revision: Feb. 29, 2016
(C) 2016 Soonchunhyang Medical Research Institute This is an Open Access article distributed under the terms of the Creative Commons Attribution Non-Commercial License (http://creativecommons.org/licenses/by-nc/4.0/). 
pacted to compacted layer ratio exceeded 2:1 measured in endsystole in the apical 4-chamber (Fig. 3A) and parasternal short axis view (Fig. 3B). Color Doppler echocardiogram showed flow in the intertrabecular recesses, confirming communications between the recesses and the ventricular cavity (Fig. 4). Grade 4 mitral regurgitation and LV posterior wall hypokinesia were noted. The LV ejection fraction by biplane Simpson method was $45 \%$. Left atrium and left ventricle were dilated. Coronary arterial pat-

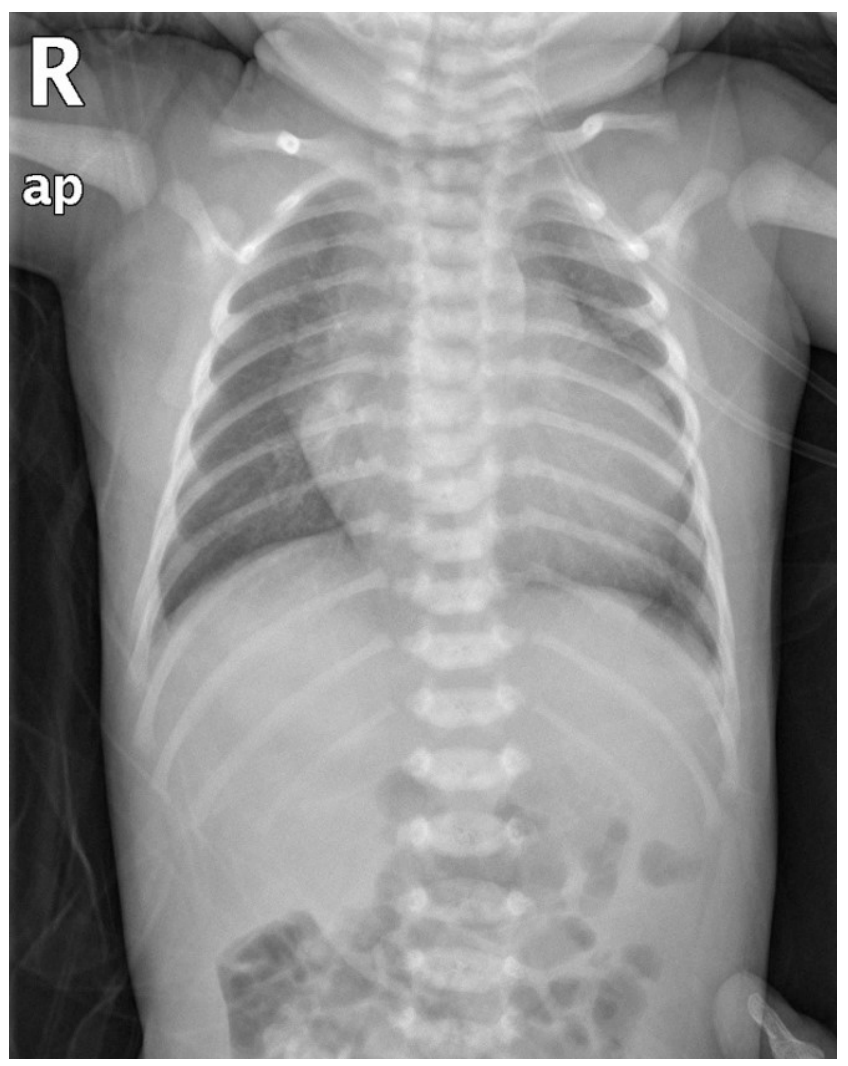

Fig. 1. Chest X-ray showing a cardiomegaly. tern was normal. Congenital heart diseases were not found.

The diagnosis of LVNC with myocardial infarction was established. Milrinone and dobutamine were infused continuously. Heparinization was started for thrombolysis and was given for 3 weeks until normalization of troponin T. Aspirin was given for antiplatelet effect. On day 4 of hospitalization, the patient was extubated successfully.

TAZ gene mutation confirmed by Sanger sequencing was detected in the patient. His mother and elder sister had the same TAZ gene mutation and were unaffected heterozygous. TAZ mutation was not detected in his father. After 3 months of admission, the patient was discharged with heart failure medication and aspirin.

\section{DISCUSSION}

LVNC is a rare form of cardiomyopathy and its clinical spectrum ranges from no symptoms to congestive heart failure, arrhythmias, and systemic thromboembolism.

The first discovered genetic cause of isolated LVNC was BHTS. BHTS was first described in 1983, as an X-liked recessive disease of cardiomyopathy, neutropenia, and skeletal myopathy [2]. Mortality is high in infancy and early toddler years due to heart failure and severe bacterial infection [1]. BTHS is secondary to loss-offunction mutations in the TAZ gene located on chromosome $\mathrm{Xq} 28$, which encodes for TAZ [3]. TAZ is important in the remodeling of acyl chains of immature cardiolipin to a mature form [4]. Cardiolipin is important for high energy-requiring tissues including cardiac muscle, is involved in maintaining mitochondrial structure and organizing mitochondrial super complexes, and has an important role in apoptosis [5].

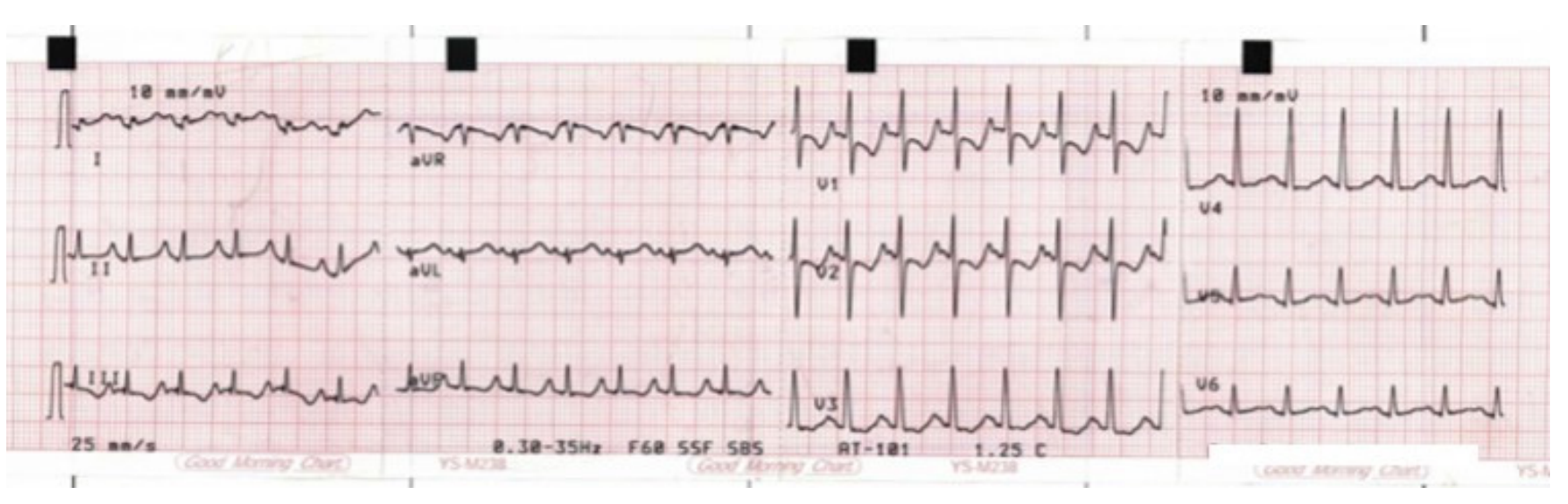

Fig. 2. Electrocardiogram showing normal sinus rhythm with ST depression and T wave inversion in lead V1 and V2 on the day of admission. 

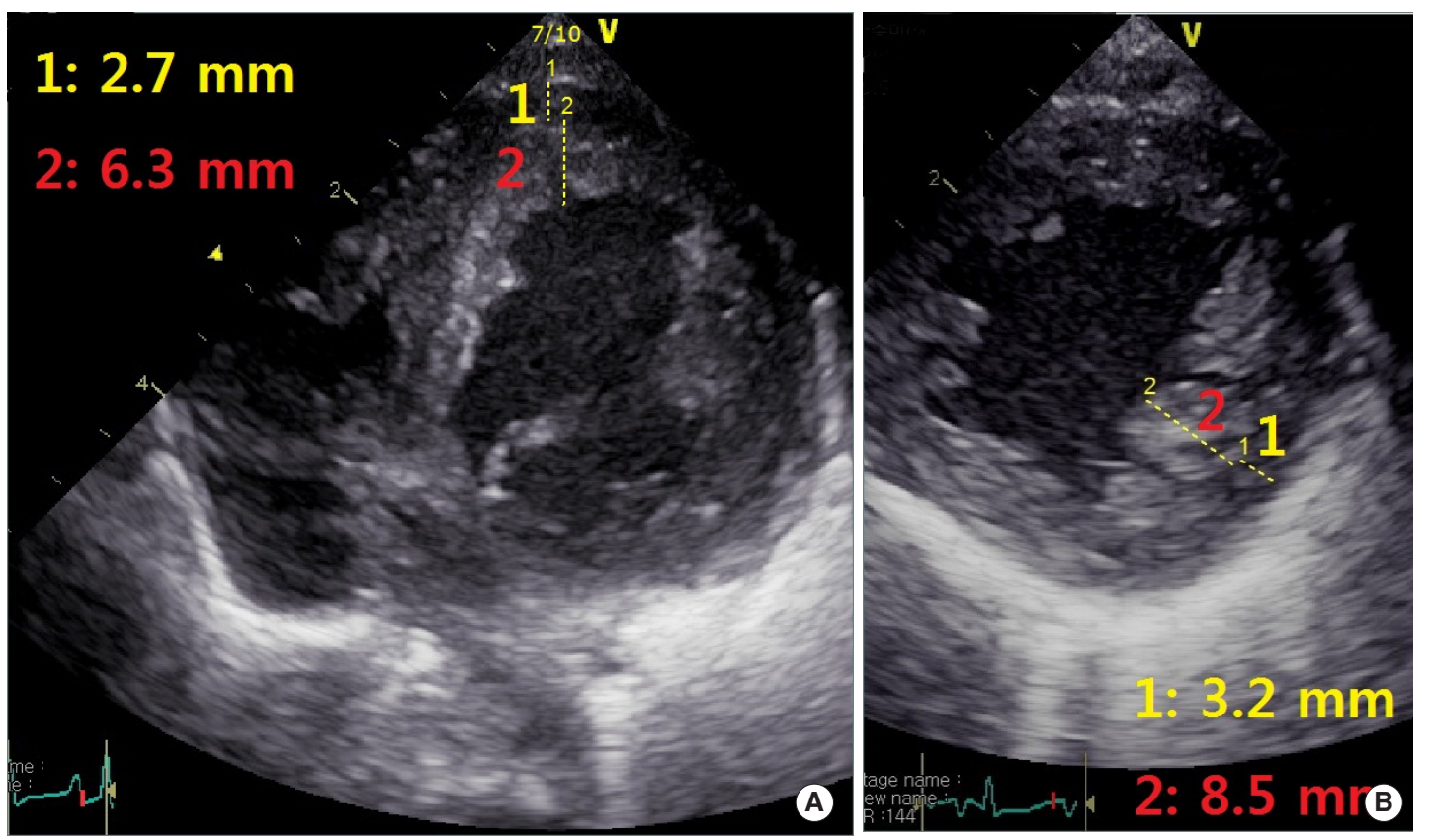

Fig. 3. Echocardiographic views. (A) Apical 4-chamber view. (B) Parasternal short axis view showing the hypertrabeculation in the left ventricular apex and demonstrates compacted layer and noncompacted layer measured in end-systole and ratio $>2$ between the noncompacted and compacted layer.

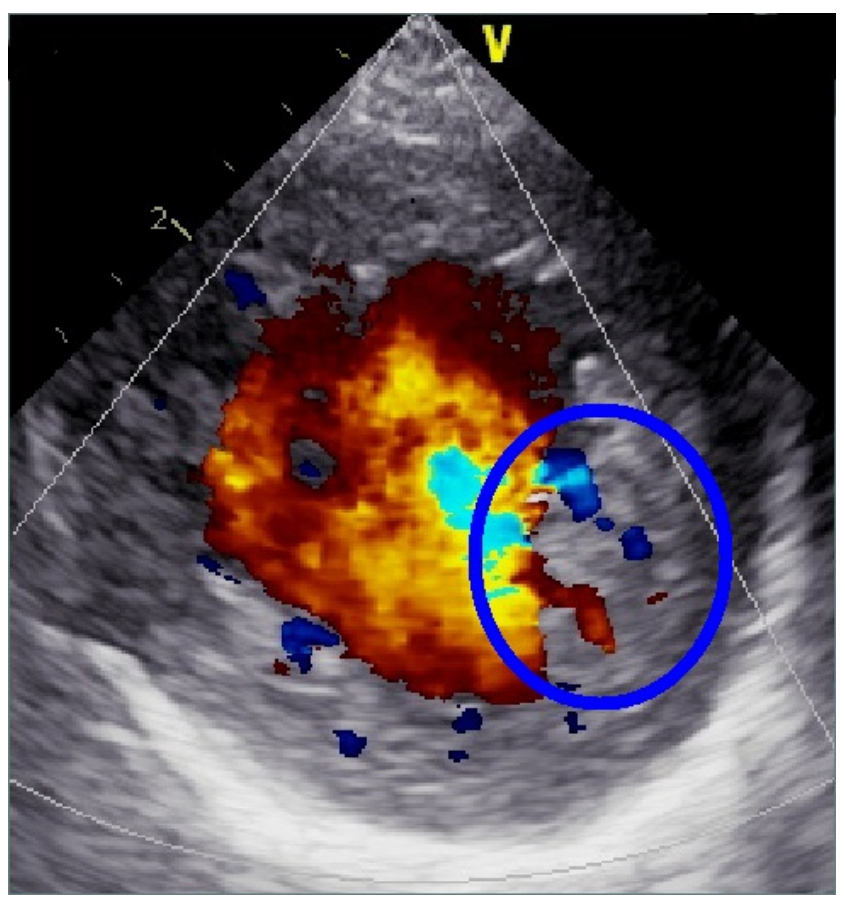

Fig. 4. Color Doppler echocardiogram showing flow (blue circle) in the intertrabecular recesses, confirming communication between recesses and the ventricular cavity.

Cardiomyopathy is the presenting manifestation in the majority of cases; $73 \%$ in one study [6]. Patients most commonly develop early onset cardiomyopathy during fetal life and in infancy [7].
The cardiomyopathy follows an undulating course in which the cardiac tissue can undergo remodeling [8]. In many affected individuals, the cardiomyopathy improves and in some it stabilizes after the toddler years [9]. Cardiomyopathy is LVNC or dilated cardiomyopathy with or without endocardial fibroelastosis, and it is rarely hypertrophic cardiomyopathy.

Specific echocardiographic criteria have been recommended for establishing the diagnosis of LVNC [10]. First is a two-layer structure with a compacted thin epicardial band and a much thicker noncompacted endocardial layer of trabecular meshwork with deep intertrabecular recesses with a maximal end-systolic ratio of noncompacted-to-compacted layer of $>2$. The second is the segmental involvement of the apex and the inferior and lateral walls at the mid-ventricular level. The third is color Doppler echocardiographic finding of blood flow from the LV cavity perfusing the trabecular recesses.

Diagnosis of BTHS is suggested by typical findings and is established in a male proband with detection of a TAZ pathogenic variant on molecular genetic testing.

In the presence of ventricular dysfunction, diuretics, betablockers, and/or vasodilators are indicated. Cardiac transplantation has been successful when heart failure is intractable [6]. Standardized cardiac evaluation including echocardiogram, electrocardiogram, and Holter monitoring should be performed to 
screen for asymptomatic arrhythmias at least yearly.

In this case, myocardial infarction seemed be due to coronary thromboembolism from a dislodged thrombus in the LV. We initiated anticoagulation. Aspirin should be considered for prevention of embolic complication at the time of initial diagnosis of LVNC [1].

We report a rare newborn case of LVNC with BTHS manifested with heart failure and complicated with myocardial infarction. We will continue management of heart failure and prevention of thromboembolism and prepare for arrhythmia. In addition, longterm serial follow-up care for BTHS is essential.

\section{REFERENCES}

1. Ferreira C, Thompson R, Vernon H. Barth syndrome. In: Pagon RA, Adam MP, Ardinger HH, Wallace SE, Amemiya A, Bean LJH, et al, editors. GeneReviews. Seattle (WA): University of Washington; 2014. p. 1993-2015.

2. Barth PG, Scholte HR, Berden JA, van der Klei-van Moorsel JM, LuytHouwen IE, van 't Veer-Korthof ET, et al. An X-linked mitochondrial disease affecting cardiac muscle, skeletal muscle and neutrophil leucocytes. J Neurol Sci 1983;62:327-55.
3. Ichida F, Tsubata S, Bowles KR, Haneda N, Uese K, Miyawaki T, et al. Novel gene mutations in patients with left ventricular noncompaction or Barth syndrome. Circulation 2001;103:1256-63.

4. Vreken P, Valianpour F, Nijtmans LG, Grivell LA, Plecko B, Wanders RJ, et al. Defective remodeling of cardiolipin and phosphatidylglycerol in Barth syndrome. Biochem Biophys Res Commun 2000;279:378-82.

5. Gonzalvez F, Gottlieb E. Cardiolipin: setting the beat of apoptosis. Apoptosis 2007;12:877-85.

6. Roberts AE, Nixon C, Steward CG, Gauvreau K, Maisenbacher M, Fletcher M, et al. The Barth Syndrome Registry: distinguishing disease characteristics and growth data from a longitudinal study. Am J Med Genet A 2012;158A:2726-32.

7. Steward CG, Newbury-Ecob RA, Hastings R, Smithson SF, Tsai-Goodman B, Quarrell OW, et al. Barth syndrome: an X-linked cause of fetal cardiomyopathy and stillbirth. Prenat Diagn 2010;30:970-6.

8. Pignatelli RH, McMahon CJ, Dreyer WJ, Denfield SW, Price J, Belmont JW, et al. Clinical characterization of left ventricular noncompaction in children: a relatively common form of cardiomyopathy. Circulation 2003;108:2672-8.

9. Rigaud C, Lebre AS, Touraine R, Beaupain B, Ottolenghi C, Chabli A, et al. Natural history of Barth syndrome: a national cohort study of 22 patients. Orphanet J Rare Dis 2013;8:70.

10. Jenni R, Oechslin E, Schneider J, Attenhofer Jost C, Kaufmann PA. Echocardiographic and pathoanatomical characteristics of isolated left ventricular non-compaction: a step towards classification as a distinct cardiomyopathy. Heart 2001;86:666-71. 